\title{
EFFECT OF PRESERVATION PROCEDURES ON THE BODY SHAPE OF THE GOLDEN MOJARRA, DIAPTERUS AUREOLUS (ACTINOPTERYGII: PERCIFORMES: GERREIDAE), AND ITS REPERCUSSIONS IN A TAXONOMIC STUDY
}

\author{
Francisco Javier VERGARA-SOLANA, Francisco Javier GARCÍA-RODRÍGUEZ*, \\ and José DE LA CRUZ-AGÜERO
}

\author{
Instituto Politécnico Nacional, Centro Interdisciplinario de Ciencias Marinas, \\ Colección Ictiológica, La Paz, Baja California Sur, México
}

\begin{abstract}
Vergara-Solana F.J., García-Rodríguez F.J., De La Cruz-Agüero J. 2014. Effect of preservation procedures on the body shape of the golden mojarra, Diapterus aureolus (Actinopterygii: Perciformes: Gerreidae), and its repercussions in a taxonomic study. Acta Ichthyol. Piscat. 44 (1): 65-70.
\end{abstract}

\begin{abstract}
Background. In taxonomic studies of fish, the use of preserved samples has been a common practice. Under the framework of morphometrics, the effect of the preservation techniques on body shape is rarely taken into account. Changes during preservation can cause errors in the results, which may eventually lead to wrong conclusions. To explore the effect of a traditional preservation procedure, we quantified the changes in body shape and size of the golden mojarra, Diapterus aureolus (Jordan et Gilbert, 1882), using geometric morphometrics.

Materials and methods. Fish fresh samples were photographed and frozen for at least seven months. Then, they were set in $10 \%$ formaldehyde, and passed through a wash of tap water and submerged in $70 \%$ ethanol. After five months the samples were photographed again. The differences between the mean shapes of two data groups (fresh fish and fixed specimens) were calculated by using the Procrustes distance. Effects associated with preservation were visualized by comparing the mean shape from each group, using a thin plate spline. A canonical variate analysis was carried out to detect the degree of intra- and inter-specific variation with $D$. brevirostris as an outgroup. Also, matrices of correct classification, based on Mahalanobis distances, were obtained.

Results. Procrustes distance between the two data sets was statistically significant $(P<0.001)$, suggesting that the fixation process produces changes in body shape. Canonical Variate Analysis verified that there were significant differences among three groups (fresh D. aureolus, fixed D. aureolus, and D. brevirostris; $P<0.001$ for both CV1 and CV2), which were correctly classified (98.9\%). In spite of the significant differences detected between the fresh and fixed data sets, these were less than those found in the outgroup. The pooled data of all specimens belonging to D. aureolus (fresh and fixed) produced a definitive correct classification (100\%) between $D$. aureolus and D. brevirostris, indicating that the differences caused by the preservation method is not enough to confound species and, consequently, taxonomic integrity was totally acceptable.

Conclusion. Our results show a change in size and shape that are consistent with changes obtained with this and other methods applied to other species: generally shapes change and sizes tend to shrink with preservation of specimens. This is probably caused by dehydration from freezing and thawing, exposure to ethanol, and dissolution of skeletal structures caused by formaldehyde. While this effect was clear, it was not enough to confuse species. Caution is advised when working with groups with a close relation (populations or not clearly-defined species). We recommend a similar exercise with a case study with these levels of divergence.
\end{abstract}

Keywords: geometric morphometrics, preservation methods, ethanol, formaldehyde, freezing, taxonomic bias

\section{INTRODUCTION}

Taxonomic, phylogenetic, or population studies of fishes usually require preserved specimens deposited in collections or museums, which are used to quantify variations in shape and size. This is clearly justified for convenience and lower costs of sampling. However a bias may be incorporated into the findings when preserved specimens are compared with fresh caught specimens.

Research efforts have focused on quantification of morphological effects caused by the preservation procedure, but mostly the studies involve crustaceans, amphibians, annelids, and fish larvae (Thibault-Botha and Bowen 2004,

\footnotetext{
${ }^{*}$ Correspondence: Dr. Francisco Javier García-Rodríguez, Instituto Politécnico Nacional, Centro Interdisciplinario de Ciencias Marinas, Colección Ictiológica, Avenida Instituto Politécnico Nacional s/n, Colonia Playa Palo de Santa Rita, La Paz, Baja California Sur, México 23096, phone: 52 (612) 122 5344 ext. 82407, fax: 52 (612) 122 5322, e-mail: (FJGR)fjgarciar@ipn.mx, (FJVS) vs_fj@yahoo.com, (JDLCA) jcruz@ipn.mx.
} 
Gagliano et al. 2006, Costa-Paiva et al. 2007, Põllupüü 2007, Deichmann et al. 2009). Morphological variations associated with preservation of juvenile or adult fishes have rarely been reported. Changes have mainly been based on length or proportion measurements (Leslie and Moore 1986, Sagnes 1997, Smith and Walker 2003, Paradis et al. 2007, Florin and Lingman 2008, Wessels et al. 2010, Lee et al. 2012), or length-weight relations (Al-Hassan et al. 2000, Ogle 2009, Beamish et al. 2011). To our knowledge, few studies explore the effect of preservation by taking advantage of the benefits of geometric morphometrics (BerbelFilho et al. 2013, Gaston et al. 2013, Martinez et al. 2013).

Previous studies of preserved fishes mainly focused on the analysis of some of the stages of the preservation process (Sagnes 1997, Ogle 2009, Wessels et al. 2010, Martinez et al. 2013) or else they compared the steps of the process in an independent way (Al-Hassan et al. 2000). A more effective approach for evaluating extreme changes in fishes should be implemented, using the combined application of the techniques for preservation of fishes stored in ichthyological collections. These may include freezing the sample, fixation with formaldehyde, and removal of formaldehyde with alcohol baths until it is finally stored in alcohol at 70\%. Although it is known that there is an effect caused by preservation (Martinez et al. 2013), it is necessary to explore whether this could affect the conclusions in a given study.

In this study, geometric morphometrics was used to measure the changes in body shape derived from the preservation process in the golden mojarra, Diapterus aureolus. This approach permits analysis of morphological variation more comprehensively and provides a clearer view of deformation when thin plate splines are used (Bookstein 1989, Zelditch et al. 2004). It also permits a direct comparison with the results obtained by Martinez et al. (2013). Additionally, we carried out an exercise to explore potential deformation when making interspecific comparisons. Like Berbel-Filho et al. (2013), we quantified whether shape changes caused by preservation incorporate a bias in a given study.

\section{MATERIALS AND METHODS}

Thirty specimens of the golden mojarra, Diapterus aureolus, were collected off the coast of Nayarit, Mexico between December 2009 and March 2010. Fresh samples were photographed with a digital camera placed on a stand. The samples were frozen until October 2010; then, they were set for nine days in $10 \%$ formaldehyde. Afterwards, the formaldehyde was rinsed out with tap water and the specimens were passed through an ethanol wash and then submerged in $70 \%$ ethanol. The samples were stored until March 2011 and photographed again using the same equipment and procedure. Based on Sagnes (1997) and Al-Hassan et al. (2000), the fixation time was sufficient to record the maximum effect caused by the fix- ation process. A sample of short-beaked mojarra, Diapterus brevirostris (Sauvage, 1879) $(n=43)$, from the Ichthyological Collection (CI) of CICIMAR-IPN was used as an outgroup. The sample was collected between 1981 and 2002 off the coast of Baja California Sur, Mexico.

The photographs were used to generate the configurations of landmarks and semi-landmarks used in the analysis (Zelditch et al. 2004). The configuration consists of a constellation of 16 marks (12 landmarks and 4 semilandmarks), representing the overall body shape of each fish (Fig. 1). All marks were obtained using the program TpsDig View 1.4* The standard length was estimated considering the tip of the snout (landmark 1) and the intersection of the lateral line and the caudal fin (landmark 9) using Tmorphgen 6 software**. This distance is calculated by taking as a reference a distance known between two marks given in a rule included in the photograph. The effects of rotation, scale, and position were eliminated by using the Generalized Procrustes method with the morphometrics software CoordGen6**.

The differences between the mean shapes of two data groups (fresh fish and fixed specimens) were calculated by using the Procrustes distance. The significance of the test was based on bootstrapping to determine whether observed $F$-value could have arisen by chance considering the distribution of bootstrapped $F$-values obtained from 900 permutations. This was done with the TwoGroup software*. The morphological modifications that are associated with preservation were visualized by comparing the mean shape from each group, using a thin plate spine.

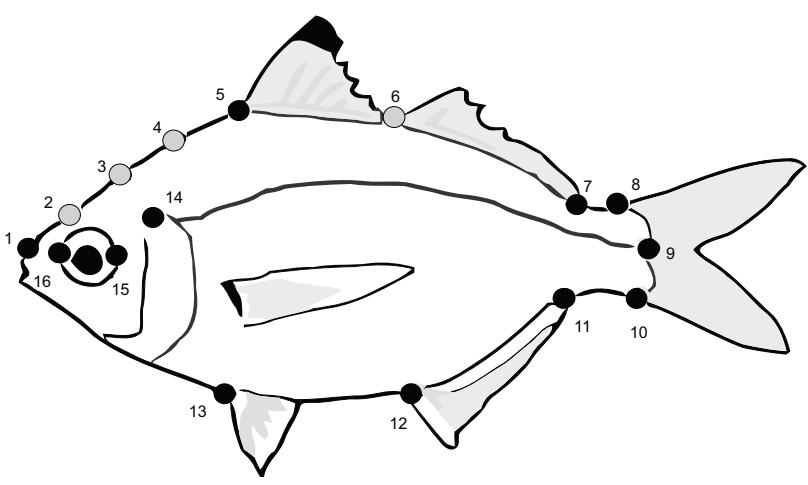

Fig. 1. Graphic representation of the marked configuration used to represent the shape of golden mojarra, Diapterus aureolus, for morphometric analysis; Gray dots represent semi-landmarks and black dots landmarks: $1=$ tip of the snout, $5=$ anterior insertion of the dorsal fin, $7=$ posterior insertion of the dorsal fin, $8=$ dorsal insertion of the caudal fin, $9=$ intersection of lateral line and the caudal fin, $10=$ ventral insertion of the caudal fin, $11=$ posterior insertion of the anal fin, $12=$ anterior insertion of the anal fin, $13=$ anterior insertion of the pelvic fin, $14=$ dorsal end of the operculum, $15=$ posterior margin of the eye, $16=$ anterior margin of the eye

\footnotetext{
${ }^{*}$ http://life.bio.sunysb.edu/morph

${ }^{* *}$ http://www3.canisius.edu/ sheets/morphsoft.html
} 
Collaterally, canonical variate analysis (CVA) was carried out to detect the degree of intra- and inter-specific variation with Diapterus brevirostris as an outgroup. This analysis was performed using the scores obtained from the first ten principal components $(91 \%$ of variance explained), since we wanted to reduce the number of original variables considering the sample size in the smallest group $(n=30)$. This analysis was performed using the program CVAGen $6 \mathrm{~m}^{*}$. A matrix of correct classification, based on Mahalanobis distances, was obtained. Subsequently, these distances were used to generate a dendrogram based on the UPGMA algorithm, as implemented in the program STATISTICA ${ }^{\circledR} 8.0$ (StatSoft). Finally, all organisms belonging to Diapterus aureolus (fresh and fixed) were pooled and a new matrix of an inter-specific correct classification based on Mahalanobis distances was obtained from a previous similar statistical analysis.

Ethical issues. The fish species in this study are not listed in any section of the country (Norma Oficial Mexicana-NOM-094) or in the Convention on International Trade in Endangered Species of Wild Fauna and Flora (CITES) as endangered or subject to special protection. Specimens were treated with concern for reducing potential suffering.

\section{RESULTS}

The average length in the fresh samples of Diapterus aureolus was $8.7 \mathrm{~cm}$ (minimum $7.3 \mathrm{~cm}$ and maximum $9.3 \mathrm{~cm}$ ) and the average length in preserved samples was $8.2 \mathrm{~cm}$ (about $-5.7 \%$ ) (minimum $6.9 \mathrm{~cm}$ and maximum $8.8 \mathrm{~cm}$ ). The differences were not statistically significant $(t=1.256$; $\mathrm{DF}=58, P=0.21)$.

Procrustes distance between the two data sets was statistically significant $(F=14.73, \mathrm{DF}=60,1 ; P=0.001)$, suggesting that the fixation process produces changes in body shape. Variations in the shape were mainly found on the ventral side, possibly as a consequence of the injection of formaldehyde into the abdominal cavity, which enlarged this area. The rest of the body was contracted, mainly in the anterior dorsal area and in the caudal peduncle, which showed a tendency to fold (Fig. 2).

CVA verifies that there were significant differences among three groups (fresh Diapterus aureolus, fixed D. aureolus, and D. brevirostris; Wilk's Lambda $=0.045$, $P<0.001$ for CV1 and $0.42, P<0.001$ for CV2) (Fig. 3), which were correctly classified (98.9\%; Table 1$)$. In spite of the significant differences detected between the fresh and fixed data sets, these were less than those found in the outgroup. CV1 explained $85.9 \%$ of the variance among groups and discriminated $D$. aureolus from $D$. brevirostris. The remaining $14.1 \%$ of the variance, associated with CV2, mainly explained the effect caused by the preservation procedure in $D$. aureolus, since it discriminated the fresh data set from the fixed data set (Fig. 3). Results from the dendrogram clearly supported a greater relation between data coming from D. aureolus specimens (Fig. 3). The pooled data of all specimens belonging to D. aureolus (fresh and fixed) produced a definitive correct classification (100\%) of $D$. aureolus and $D$. brevirostris (Table 2), indicating that the differences caused by the preservation method are not enough to confuse species and, consequently, taxonomic integrity was totally acceptable.

\section{DISCUSSION}

Contractions in body shape (Fig. 2) were concordant with the reduction in body size. Although not statistically significant, the reduction in size was associated with the preservation process because the same sample was used in the analysis. Similarly, other studies have reported a reduction in size caused by preservation by means freezing, formaldehyde, and ethanol (Sagnes 1997, Al-Hassan et al. 2000). The reasons why the fixation process produces these contractions may be associated with of the following:

- Loss of water in tissues from freezing and thawing and exposure to ethanol (Ogle 2009) or

- Dissolution of skeletal structures caused by formaldehyde (Gagliano et al. 2006).

- Of these three stages, the formaldehyde produces the smallest shrinkage (Paradis et al. 2007).

Previous studies indicate that not all species react in the same way when subjected to a fixation technique (Ogle 2009, Martinez et al. 2013). Some authors have proposed inter-specific differences in the proportion of organic molecules, such as lipids and proteins in tissues, as a possible explanation for this effect (Sagnes 1997, AlHassan et al. 2000). An explanation consistent with previous findings is the inter-specific amount and proportion of red and white muscle (Martinez et al. 2013). The fact that shrinking was not homogeneous throughout the body may be explained by tissues not being arranged in the same way (Fig. 2).

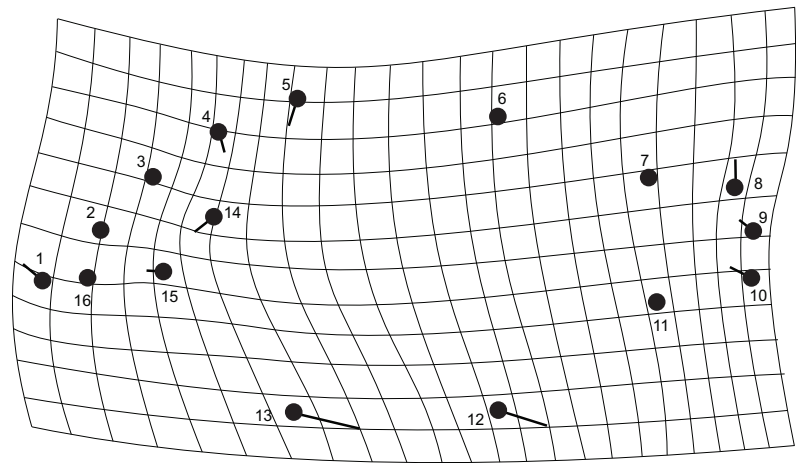

Fig. 2. Thin plate spline showing the body deformation recorded in fresh specimens of golden mojarra, Diapterus aureolus, when they passed through the fixation method; Black dots denote the average shape of fresh fishes and vector strength and direction of deformation toward the mean shape of the fixed specimens; Magnification $=3 \times$

\footnotetext{
${ }^{*}$ See footnote on page 66.
} 
Our findings indicate that preservation methods in fishes may affect body shape. Extreme caution when using morphometrics with preserved organisms has been suggested, like using bone structures examined by X-rays (Martinez et al. 2013). However, the intensity of this effect with respect to expected variance has not been evaluated.

The preservation effect in Diapterus aureolus was not sufficient to produce differences higher than those found at the species level, for example between $D$. aureolus and D. brevirostris (Table 2). These results should not necessar-
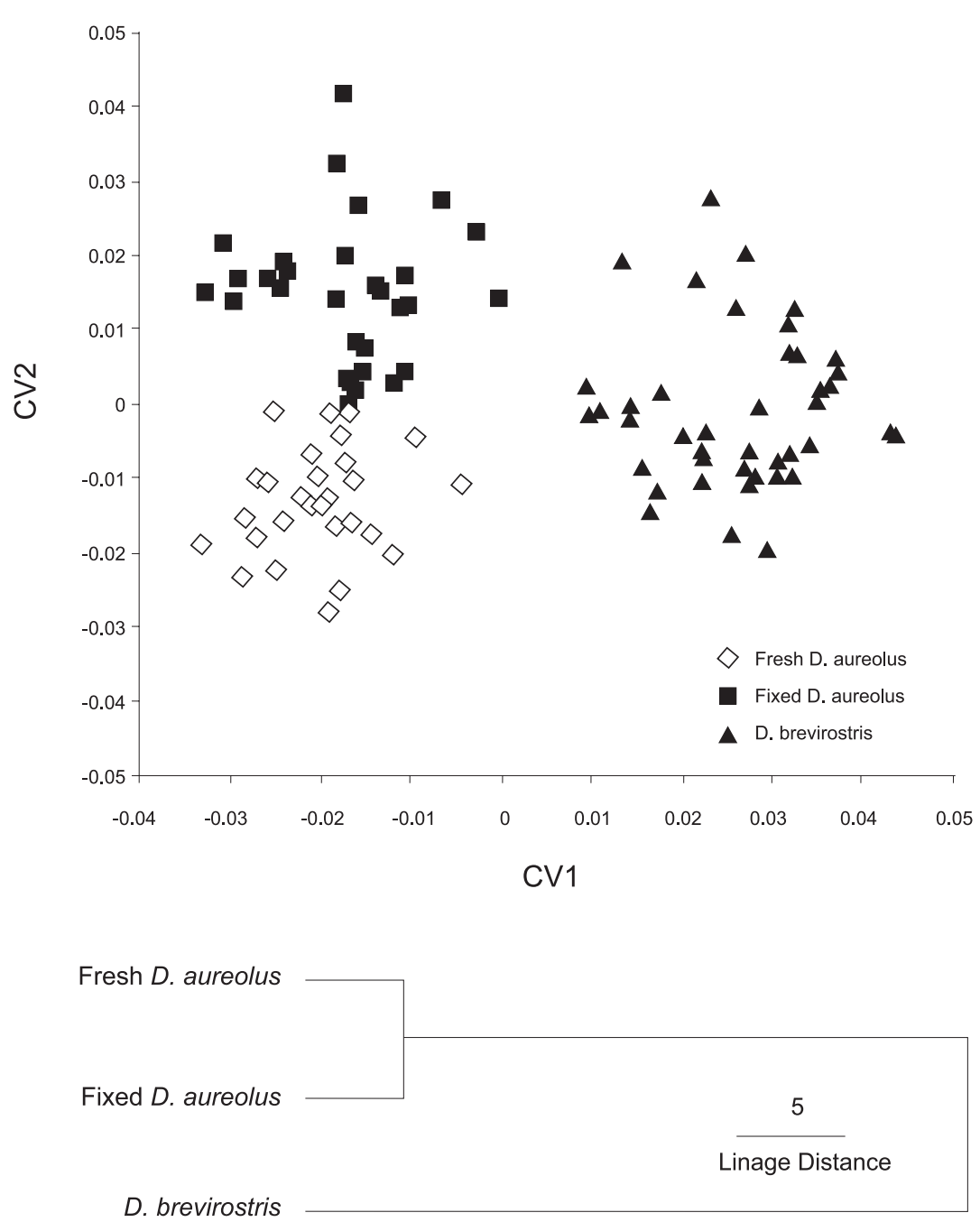

Fig. 3. Graphs generated from the scores of the two canonical variables generated from the CVA (above); Dendrogram constructed with the Mahalanobis distance using the UPGMA algorithm in addition to showing the affinities between the three groups used in the CVA (below)

Table 1

Table 2

Correct assignment matrix showing the percentage of samples of Diapterus spp. correctly assigned to their group of origin

\begin{tabular}{lccr}
\hline & Fresh DA & Fixed DA & DB \\
\hline Fresh DA & 100 & 0 & 0 \\
Fixed DA & 3.3 & 96.7 & 0 \\
DB & 0 & 0 & 100 \\
\hline
\end{tabular}

\begin{tabular}{lcc}
\hline & Pooled & D. brevirostris \\
\hline Dooled D. aureolus & 100 & 0 \\
D. brevirostris & 0 & 100 \\
\hline
\end{tabular}

DA = Diapterus aureolus, DB = Diapterus brevirostris. ily be found when other taxonomic groups are studied, since the effect of formaldehyde can be different (Sagnes 1997, Al Hassan et al. 2000, Martinez et al. 2013). Similar attention should be considered in studies of intra-specific variation (population or stock analysis), since small differences caused by preservation could be confused with the natural all variation expected a priori. This could bias the conclusions. These considerations were also indicated by BerberFilho et al. (2013) since they found significant changes in the geometric morphometric in individuals of the peacock 
bass, Cichla kelberi Kullander et Ferreira 2006, before and after freezing and alcohol preservation.

Considering that preservation methods can have an effect on changes in the shape of the fishes and, consequently, bias results, especially in studies at population level, we suggested using fresh samples as much as possible and simplifying the preservation method, for example by reducing the time devoted to freezing. Unfortunately, fresh fishes cannot always be collected, so the use of fishes found in collections or museums can sometimes be necessary. For this reason, the usefulness of creating an equation for determining the effect of preservation has been advocated (Simon 2013), but as Martinez et al. (2013) emphasize, this is relatively simple when working with weight and length because they are straightforward measures. Using either 2D or 3D morphometry to predict changes produced by preservation in different body parts is much more complicated because knowledge of tissue composition and arrangement in each species is not readily available. An alternative may be to create a correction factor that takes into account phylogeny, as closely related species tend to have similar body shapes. We would expect that the effect of preservation would act similarly in these species. One application of this idea is the similarity of deformation caused by preservation in Eucinostomus argenteus Baird et Girard, 1855, another species in the Gerreidae family (Martinez et al. 2013), and deformation in Diapterus aureolus, as reported in our study. Both species tended to contract, especially in the anterior dorsal area and the caudal peduncle, which has a tendency to fold. This pattern differs from those observed for Pomadasys corvinaerformis (Steindachner, 1868) (see Martinez et al. 2013).

The results of the presently reported study suggest that more experimentation should be carried out in order to support the use of preserved organisms in phylogenetic and population studies applying morphometric geometric analysis.

\section{ACKNOWLEDGEMENTS}

We thank E. De Luna for advice during this investigation, V.M. Cota for laboratory assistance, J.G. Chollet for suggesting this topic, and J.T. Nieto for providing samples. The study was funded by Instituto Politécnico Nacional (grants SIP-20071113, SIP-20080573, and SIP-20090333). Present authors: FJGR and JDA acknowledge herewith the support of the grants of EDI-IPN, COFAA-IPN, and SNI-CONACYT. FJVS is a recipient of fellowship grants from PIFI-IPN and CONACYT. Finally, we also thank Roger Dunne for his assistance in reviewing the manuscript in English language.

\section{REFERENCES}

Al-Hassan L.A.J., Bujawari J.A., El-Silini O.A. 2000. The effect of some preservatives and freezing on certain body dimensions of two species of the family Mullidae collected from Benghazi waters, Libya. Acta Ichthyologica et Piscatoria 30 (2): 127-136.

Beamish F.W.H., Plongsesthee R., Chanintarapoomi P., Nithirojpakdee P. 2011. Total length-weight relationships among Thai freshwater fishes and the influence of capture location and preservation. Journal of Applied Ichthyology 27 (3): 955-958. DOI: 10.1111/j.1439-0426.2010.01620.x

Berbel-Filho W.M., Jacobina U.P., Martinez P.A. 2013. Preservation effects in geometric morphometric approaches: freezing and alcohol in a freshwater fish. Ichthyological Research 60 (3): 268-271. DOI: 10.1007/s10228-013-0339-x

Bookstein F.L. 1989. Principal warps: Thin-plate splines and the decomposition of deformations. IEEE Transactions on Pattern Analysis and Machine Intelligence 11 (6): 567-585. DOI: $10.1109 / 34.24792$

Costa-Paiva E.M., Paiva P.C., Klautau M. 2007. Anaesthetization and fixation effects on the morphology of sabellid polychaetes (Annelida: Polychaeta: Sabellidae). Journal of the Marine Biological Association of the United Kingdom 87 (5): 1127-1132. DOI: 10.1017/ S002531540705223X

Deichmann J.L., Boundy J., Williamson G.B. 2009. Anuran artifacts of preservation: 27 years later. Phyllomedusa 8 (1): 51-58.

Florin A.-B., Lingman A. 2008. Shrinkage of flounder Platichthys flesus (L.) and turbot Psetta maxima (L.) following freezing. Journal of Fish Biology 72 (3): 731-736. DOI: 10.1111/j.1095-8649.2007.01710.x

Gagliano M., Kowalewsky S., McCormick M.I. 2006. An alternative method for the preservation of tropical fish larvae. Journal of Fish Biology 68 (2): 634-639. DOI: 10.1111/j.0022-1112.2006.00911.x

Gaston K.A., Jacquemin S.J., Lauer T.E. 2013. The influence of preservation on fish morphology in museum collections based on two species of the genus Lepomis (Actinopterygii: Perciformes: Centrarchidae). Acta Ichthyologica et Piscatoria 43 (3): 219-227. DOI: 10.3750/AIP2013.43.3.06

Lee J.-H., Kodama K., Horiguchi T. 2012. Change in body size of juvenile marbled sole Pseudopleuronectes yokohamae after preservation in ethanol. Ichthyological Research 59 (1): 49-52. DOI: 10.1007/s10228-011-0255-x

Leslie J.K., Moore J.E. 1986. Changes in lengths of fixed and preserved young freshwater fish. Canadian Journal of Fisheries and Aquatic Sciences 43 (5): 1079-1081. DOI: 10.1139/f86-136

Martinez P.A., Berbel-Filho W.M., Jacobina U.P. 2013. Is formalin fixation and ethanol preservation able to influence in geometric morphometric analysis? Fishes as a case study. Zoomorphology 132 (1): 87-93. DOI: 10.1007/s00435-0120176-x

Ogle D.H. 2009. The effect of freezing on the length and weight measurements of ruffe (Gymnocephalus cernuus). Fisheries Research 99 (3): 244-247. DOI: 10.1016/j.fishres.2009.06.009

Paradis Y., Magnan P., Brodeur P., Mingelbier M. 2007. Length and weight reduction in larval and juvenile yellow perch preserved with dry ice, formalin, and ethanol. North American Journal of Fisheries Management 27 (3): 1004-1009. DOI: 10.1577/M06-141.1

Põllupüü M. 2007. Effect of formalin preservation on the body length of copepods. Proceedings of the Estonian Academy of Sciences Biology Ecology 56 (4): 326-331.

Sagnes P. 1997. Potential artefacts in morphometric analyses of fish: effects of formalin preservation on $0+$ grayling. Journal 
of Fish Biology $\mathbf{5 0}$ (4): 910-914. DOI: 10.1006/
jfbi.1996.0352

Simon J. 2013. A correction factor for the shrinkage of total length and weight of European eels during freezing. Journal of Applied Ichthyology 29 (4): 909-911. DOI: 10.1111/ jai.12104

Smith B.B., Walker K.F. 2003. Shrinkage of 0+ carp (Cyprinus carpio L.) after preservation in ethanol. Marine and Freshwater Research 54 (2):113-116. DOI: 10.1071/ MF02089

Thibault-Botha D., Bowen B. 2004. Impact of formalin preservation on Pleurobrachia bachei (Ctenophora). Journal of Experimental Marine Biology and Ecology 303 (1): 11-17. DOI: $10.1016 /$ j.jembe.2003.10.017
Wessels G., Moloney C.L., Van Der Lingen C.D. 2010. The effects of freezing on the morphometrics of sardine Sardinops sagax (Jenyns, 1842). Fisheries Research 106 (3): 528-534. DOI: 10.1016/j.fishres.2010.10.004

Zelditch M.J., Swiderski D.L., Sheets H.D., Fink W. 2004. Geometric morphometrics for biologists: a primer. Academic Press, New York, NY, USA.

Received: 17 May 2013

Accepted: 6 February 2014

Published electronically: 31 March 2014 